\title{
INFORMATION LITERACY IN EARLY CHILDHOOD EDUCATION
}

\author{
Fatia FATIMAH ${ }^{1}$, YUSRAFIDDIN², MUHAMMADI ${ }^{2}$, Refny DELFI ${ }^{3}$ \\ DASRUL4 4 , HARNON5 5 , Zaimal GUSTI6 \\ Matematika1, Pendidikan Guru Anak Usia Dini2 ${ }^{2}$ Teknologi Pendidikan³, \\ Pendidikan Bahasa Inggris ${ }^{4}$, Pendidikan Bahasa dan Sastra Indonesia ${ }^{5}$, \\ Pendidikan Ekonomi ${ }^{6}$, Universitas Terbuka \\ Email: fatia@ecampus.ut.ac.id
}

\begin{abstract}
Literacy could be a supporter of the forefront of education. Teachers have a crucial role in filtering and remodeling data on their students. The utilization of knowledge skill has to be trained by sorting and selecting the proper media for learning whose main purpose is to extend students' intelligence. Skill coaching is a way to boost the flexibility to use learning media, particularly Early Childhood Education and Kindergartens in Lubuk Begalung, Padang. The objectives to be achieved include: to increase the insight of Early Childhood Education and Kindergarten teachers about media, and the ability of media information literacy in learning. Training methods i.e. lectures, discussions, questions, and answers, and case simulations. The conclusion obtained from this activity is that early childhood and kindergarten teachers can choose the media responsibly and able to criticize media content more intelligent in the classroom.
\end{abstract}

Keywords: Information Literacy, Media Literacy, Early Childhood Education

\section{PENDAHULUAN}

Kemampuan untuk memahami, menganalisis dan mendekonstruksi pencitraan media merupakan kemampuan yang dihubungkan dengan kemampuan individu dalam literasi. Literasi media harus dikembangkan dalam masyarakat agar masyarakat termasuk anak-anak menjadi sadar bagaimana cara media dikonstruksi dan diakses. Oleh karena itu, literasi media sangat dibutuhkan dalam menyeleksi informasi yang diberikan. Dengan kata lain, literasi media merupakan sebuah keterampilan untuk berinteraksi secara pintar dengan media.

Berbagai literatur tentang pentingnya literasi informasi dalam pembelajaran sudah dilakukan dan hasilnya positif baik untuk guru maupun siswa (Ainiyah, 2017; Yusup \& Saepudin, 2017; Hapsari, dkk., 2018; Kharizmi, 2019). Berikut beberapa penelitian terdahulu mengenai pelatihan literasi media. Pelatihan literasi media kepada para guru PAUD di Kecamatan Cicalengka Kabupaten Bandung dapat meningkatkan kapasitas pengetahuan, pemahaman, keahlian, dan keterampilan para guru dalam memilih media sebagai sumber belajar yang baik dan benar (Saepudin \& Damayani, 2016). Pengetahuan dan kemampuan media literasi siswa meningkat, dari yang tidak mengerti menjadi mengerti tentang media literasi (Rahman \& Bukhori, 2016). Gambaran kompetensi guru di Medan menunjukkan bahwa literasi dasar, literasi perpustakaan, 
dan literasi teknologi mereka dapat dianggap sudah cukup namun diperlukan pengayaan untuk meningkatkan literasi media dan visual (Anggaraeni \& Rola , 2017).

Anak-anak usia dini merupakan anak yang tengah tumbuh dengan pesat secara biologis maupun psikis. Mereka suka meniru, tanpa berupaya mengkritisinya terlebih dahulu. Literasi media pada anak-anak usia dini sangat strategis untuk dilakukan. Orang tua dan guru merupakan pihak yang paling dekat dengan anak. Oleh karena itu, kewajiban bagi orang tua dan guru untuk selalu mendampingi dan membina anakanak dalam berinteraksi dengan media.

Guru perlu memahami bahwa anak-anak usia dini lebih sering patuh kepada gurunya bila dinasihati dibandingkan jika dinasihati oleh keluarga. Oleh karena itu, guru PAUD dapat menyisipkan materi literasi media saat mengajar di kelas dengan model penayangan audio visual film kartun yang banyak digemari anak-anak. Setelah penayangan film dilanjutkan dengan dialog kepada murid mengenai isi tayangan tersebut. Dalam proses dialog tersebut perlu dijelaskan kepada para siswa mengenai kandungan informasi dalam film tersebut terutama pesan-pesan moral yang ada di dalamnya. Literasi media mengajak kita mengevaluasi tayangan dan berpikir kritis tentang pesan yang disampaikan televisi. Apakah pantas, logis, dan bermoral atau tidak.

Berdasarkan hal di atas perlu dilakukan pengabdian masyarakat kepada guru-guru Pendidikan Anak Usia Dini dengan memberikan pelatihan literasi media kepada mereka. Oleh karena itu, dosen-dosen Universitas Terbuka Padang mengadakan program pengabdian masyarakat berupa "Pelatihan Literasi Informasi Media Pembelajaran bagi Guru PAUD dan TK Kecamatan Lubuk begalung Padang".

\section{METODE PELAKSANAAN}

Metode yang digunakan untuk pengabdian masyarakat berupa Pelatihan Literasi Informasi Media Pembelajaran bagi Guru PAUD dan TK Kecamatan Lubuk begalung Padang sebagai berikut:

a. Penyampaian materi. Metode yang digunakan adalah ceramah, tanya jawab, dan demonstrasi.

b. Praktek. Metode yang digunakan sebagai berikut:

1. Peserta dibagi ke beberapa kelompok. Setiap kelompok terdiri dari lima sampai 6 orang.

2. Materi praktek adalah cara akses UT online, membuat e-mail dan pemanfaatan Guru Pintar Online

3. Praktek dilakukan selama dua jam sekaligus membahas kasus yang ditayangkan sebagai bentuk literasi media.

4. Setiap kelompok mempresentasikan hasil diskusi kelompoknya.

c. Pemberian angket kepada peserta 


\section{HASIL DAN PEMBAHASAN}

Diera digitalisasi pendidikan diharapkan mampu meningkatkan sumber daya manusia yang semakin berkompeten dalam bidang masing-masing. Tak luput dari era tersebut adalah guruguru yang mempunyai peran penting membantu meningkatkan kualitas hidup manusia yang berkelanjutan. Peran guru bermula dari pendidikan anak usia dini hingga jenjang sekolah menengah atas. Pada pembahasan ini fokus pada guru-guru PAUD dan TK dalam memanfaatkan literasi informasi. Para guru memahami bahwa ada kompetendi inti yang berperan secara domain kognitif untuk setiap mata pelajaran yaitu membekali peserta didik dalam hal 1). pengetahuan faktual, 2). konseptual, dan 3). Procedural. Hal tersebut tentunya berdasarkan rasa keingintahuan siswa tentang ilmu pengetahuan, teknologi, seni budaya terkoneksi dengan fenomena dan kejadian yang terekam melalui penglihatan mereka (Sari, 2015).

Pratiwi \& Pritanova (2017) menyebutkan bahwa konten dalam literasi yang berkembang dengan cepat melalui dunia maya, seperti media sosial maupun web site. Seperti mata uang yang mempunyai dua sisi. Sisi yang dapat meningkatkan pemahaman dan kemampuan siswa namun disisi lain ada konten-konten yang tidak mendidik dapat mempengaruhi prilaku psikologi perserta didik dan prilaku yang buruk karena merekam hal-hal yang negatif.

Tidak mudah menjadi seorang guru karena untuk menjadi guru yang baik membutuhkan penguasaan terhadap konten (bahan pelajaran/materi subjek) dan menguasai ilmu mengajar (pedagogi). Oleh karena itu, pada kegiatan ini, sajian konten dalam https://www.ut.ac.id sebagai sumber utama dalam pelatihan literasi informasi. Kriteria konten yang dipilih berdasarkan kepentingan peningkatkan pengetahuan guna memahami dan memaknai konten yang kaitannya untuk mengembangkan kepribadian dan respon sosial siswa.

Pelaksanaan pengabdian masyarakat yaitu pada tanggal 20 Juni 2019 di TK IT AI Kautsar. Peserta berasal dari guru-guru PAUD dan TK se-Kecamatan Lubuk Begalung yang berjumlah 22 orang. Rincian peserta dapat dilihat pada Tabel 1.

Tabel 1. Peserta Pelatihan Literasi Informasi

\begin{tabular}{|c|c|c|c|}
\hline No. & Nama & Tempat Mengajar & Lama Mengajar \\
\hline 1 & Arniyeti S.Pd & TK Kasih Ibu & Antara 2 sampai 6 tahun \\
\hline 2 & Atika Putri Cahyani & TK IT Al Kautsar & Belum sampai 2 tahun \\
\hline 3 & Citra Yuliastuti, S.Pd & TK Nurul Qalbi & Antara 2 sampai 6 tahun \\
\hline 4 & Dessy Anggriana & TK Nurul Qalbi & Antara 2 sampai 6 tahun \\
\hline 5 & Erlinda S.Pd & TK Nur Islam & Lebih dari 6 tahun \\
\hline 6 & Gusnarita S.Pd & TK YLPI Gaung & Antara 2 sampai 6 tahun \\
\hline 7 & Harfiyanti S.Pd & TK Nur Islam & Antara 2 sampai 6 tahun \\
\hline 8 & Itrianti S.Pd & TK Harapan Bunda & Lebih dari 6 tahun \\
\hline 9 & Kusniarti & TK Almawaddah & Lebih dari 6 tahun \\
\hline 10 & Lili Nofiyanti & TK Yapenha & Belum sampai 2 tahun \\
\hline 11 & Magdalia Elfa S.Pd & TK Alya Zahira & Antara 2 sampai 6 tahun \\
\hline 12 & Mardiana S.Pd & TK Dar-Almadinah & Lebih dari 6 tahun \\
\hline
\end{tabular}




\begin{tabular}{llll}
\hline 13 & Mariawati SR & TK IT Al Kautsar & Lebih dari 6 tahun \\
14 & Minda Hidjiia S.Pd & TK Ummi Khalifah & Lebih dari 6 tahun \\
15 & Mulyani S.Pd & TK Nur Islam & Lebih dari 6 tahun \\
16 & Nini Sriwahyuni & TK pertiwi Bungus & Belum sampai 2 tahun \\
17 & Novita Sari S.Pd & TK Ummi Khalifah & Antara 2 sampai 6 tahun \\
18 & Nur adna Oktafia S.Pd & TK Alya Zahira & Belum sampai 2 tahun \\
19 & Nurbaiti S.Pd & TK Yapenha & Lebih dari 6 tahun \\
20 & Rusfita Media & TK Aisyiyah & Lebih dari 6 tahun \\
21 & Silvi nugrah pratama & TK Nur Islam & Belum sampai 2 tahun \\
22 & Yumparida & TK IT Al Kautsar & Antara 2 sampai 6 tahun \\
23 & Yuniarti, SK & TK Nur Islam & Lebih dari 6 tahun \\
\hline
\end{tabular}

Materi yang disampaikan tentang literasi informasi media pembelajaran sudah ditentukan oleh tim pelaksanaan pengabdian dan telah didiskusikan dengan kelompok kerja guru-guru tersebut. Sehingga materi yang disampaikan sudah disesuaikan dengan kebutuhan guru-guru PAUD dan TK dalam proses pengajaran yang bersumber dari sumber media belajar yang disediakan oleh https://www.ut.ac.id tanpa harus membayar.
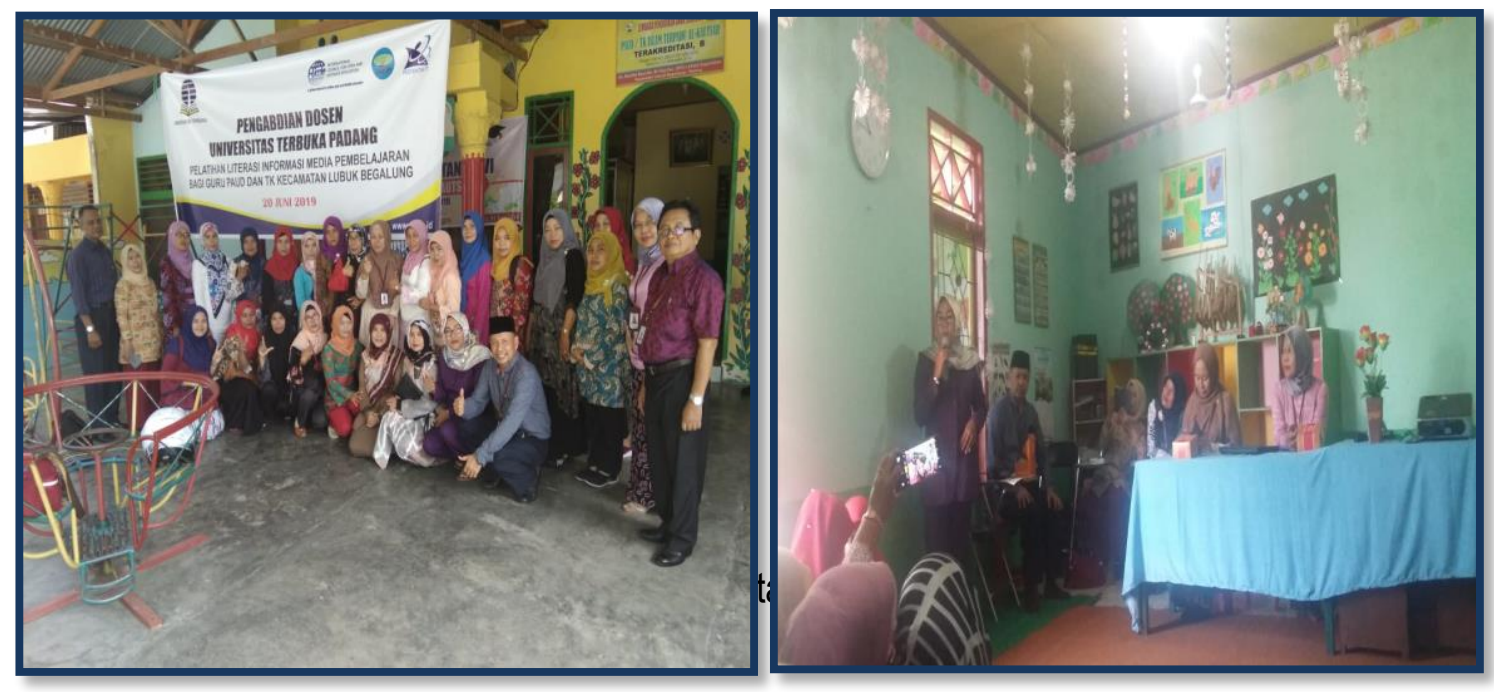
Peserta sangat antusias untuk mengikuti kegiatan. Hal ini terlihat dari cara mereka bertanya, berdiskusi dalam menyelesaikan masalah yang dikemukan baik oleh fasilitator maupun peserta yang lain. Presentasi oleh salah satu peserta merupakan salah satu metode yang diterapkan dalam pelaksanaan kegiatan ini dengan tujuan agar komunikasi tidak satu arah namun lebih kepada interaktif antara peserta dengan peserta, antara peserta dengan fasilitator (Gambar 1).

Untuk memastikan keberhasilan dan kebermanfaatan kegiatan ini, peserta diminta untuk mengisi angket mengenai kemampuan guru dalam penggunaan media pembelajaran untuk literasi informasi yang disebar ke semua peserta. Hasil angket dapat dilihat pada sajian Gambar 2 sampai Gambar 5.

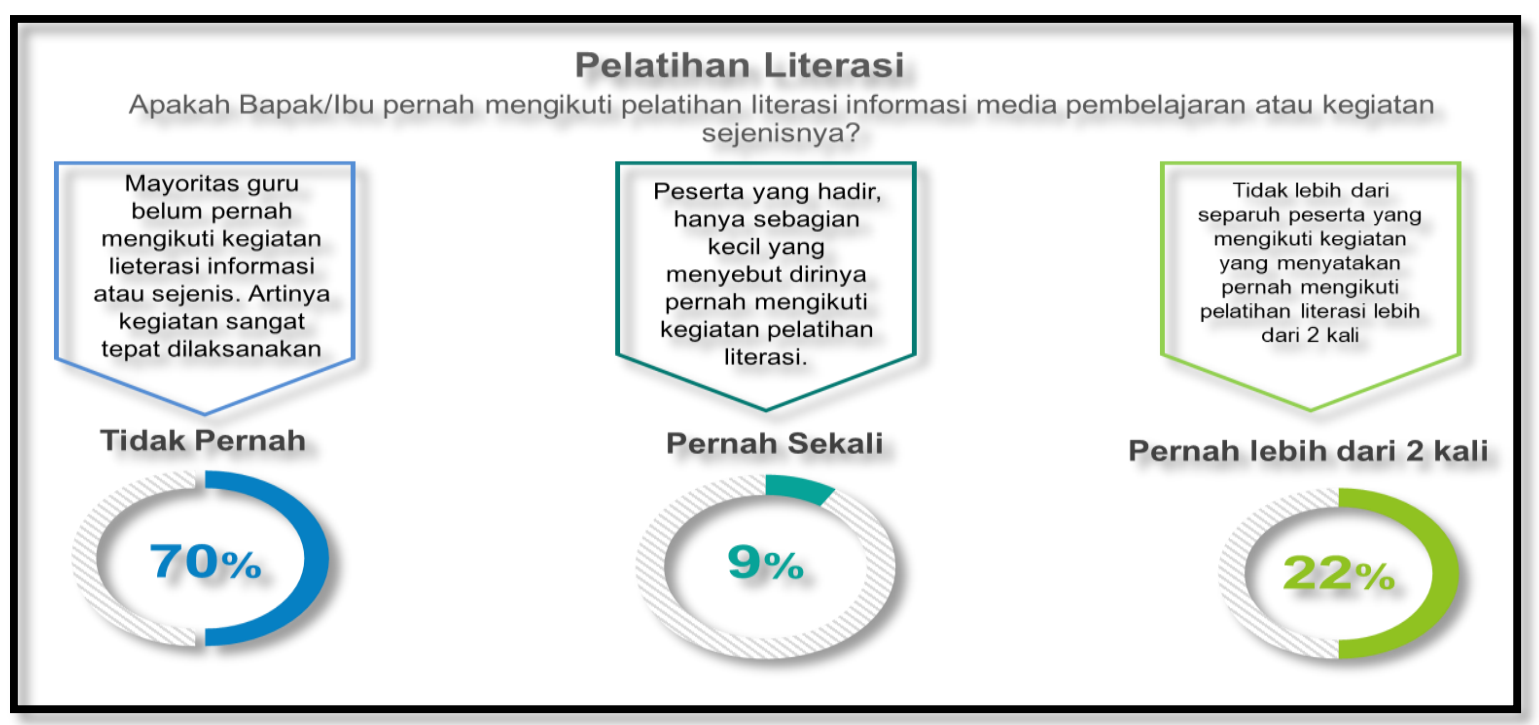

\section{Gambar 2. Pelatihan Literasi}

Pelaksanaan pelatihan ini dinilai tepat, mengingat hasil survey yang dilakukan membuktikan bahwa pengetahuan dan pemahaman guru-guru mengenai literasi informasi masih sangat minim. Hampir seluruh peserta yaitu sebanyak $70 \%$ menyatakan bahwa mereka tidak pernah mengikuti pelatihan mengenai literasi atau sejenisnya. 


\section{Menggunakan Literasi}

Apakah Bapak/lbu pernah mengajar dengan menggunakan media pembelajaran untuk literasi informasi?
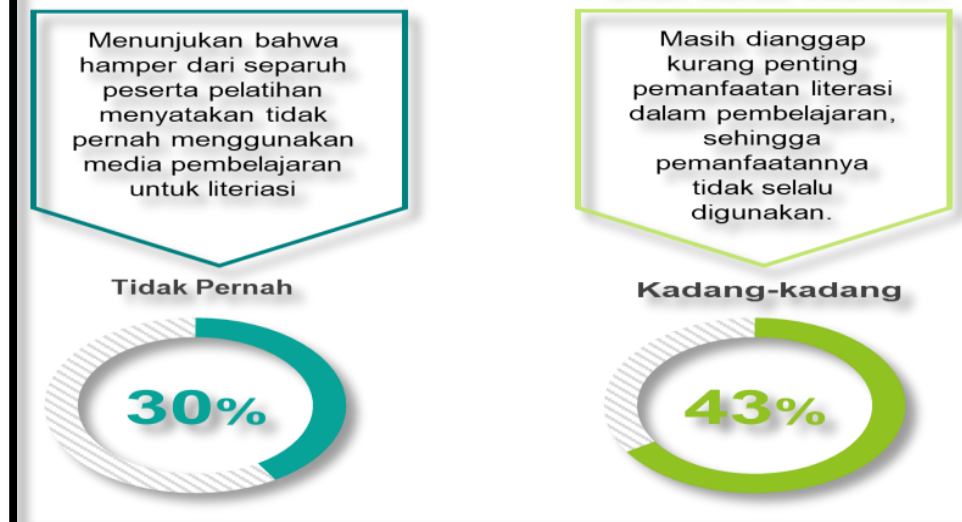

Meskipun tidak sampai separuh namun peserta menyebutkan dirinya telah memanfaatkan literasi informasi untuk dimanfaatkan sebagai media pembelajaran

\section{Gambar 3. Penggunaan Literasi}

Dimungkinkan terbentuk kolerasi antara mengikuti pelatihan dan pemanfaatan literasi,ketika tidak pernah mengikuti pelatihan menunjukan angka partsipasi yang tinggi maka berakibat pada tidak menggunakan literasi yang tinggi pula. Survey menyebutkan bahwa $43 \%$ masih kurang memanfaatkan literasi informasi dan masih mengangap penggunaannya masih kurang dibutuhkan.

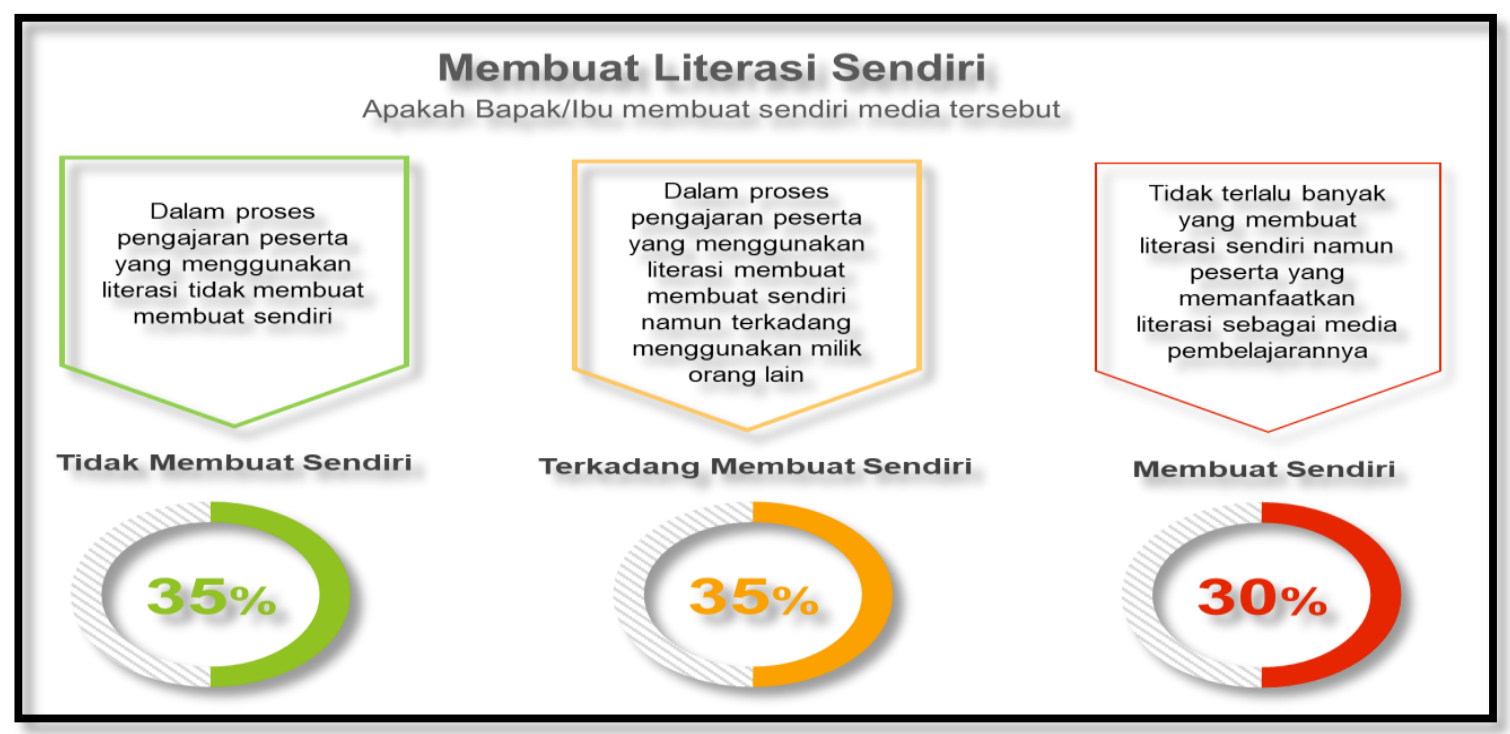

Gambar 4. Membuat Literasi Sendiri

Gambar 4 diatas telah menggambarkan keberimbangan antara membuat dan menggunakan literasi milih pihak lain, hal ini menunjukan kemampuan dan kreatifitas guru dalam mengembangkan literasi yang akan digunakan pada saat proses pengajaran. 


\section{Hambatan Menggunakan Literasi}

Apa hambatan yang dialami dalam menggunakan literasi informasi media pembelajaran?

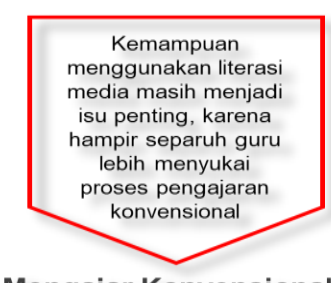

Mengajar Konvensional

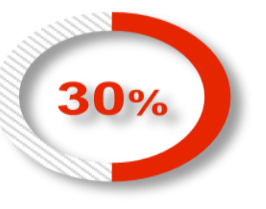

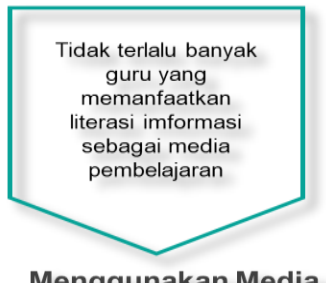

Menggunakan Media Pembelajaran

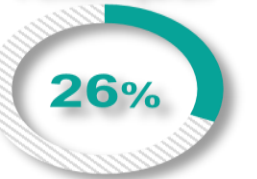

Peserta menyebutkan

bahwa mendia literasi

tidak mendukung

untuk dimanfaatkan

sebagai media

pembelajaran
Media Pembelajaran tidak medukung

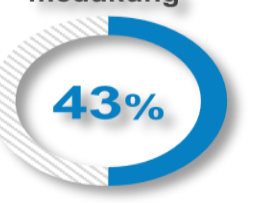

Gambar 5. Hambatan Menggunakan Literasi

Memang harus disadari bahwa sarana dan prasana disekolah selalu menjadi kendala dalam proses pembelajaran dan pengajaran. Hampir $43 \%$ peserta menyebutkan bahwa ada hambatan dalam pemanfaatan literasi untuk media pembelajaran di sekolah.

\section{KESIMPULAN}

Pemanfaatan literasi tidak lepas dari sarana dan prasana yang ada disekolah, tepatnya fasilitas pendukung agar pemilihan literasi sebagai media pembelajaran dapat dimanfaatkan. Agar keterampilan, pengetahuan dan pemahaman guru-guru semakin meningkat perlu dilakasanakan pelatihan berkelanjutan dengan level pelatihan yang berbeda untuk tiap jenjang level pendidikannya.

Guru berperan penting dalam memilih dan memilah literasi informasi untuk dimanfaatkan sebagai media pembelajaran, kemampuan guru juga harus ditingkatkan dengan pemahaman mengintegrasikan literasi yang kontennya akan melebur kedalam kurikulum, pembelajaran, proses mengajar dan akhirnya bermuara kepada siswa. Literasi apapun mungkin mempunyai manfaat bagi yang mempunyai kepentingan, sehingga kontenlah yang perlu menjadi fokus para guru. Pengetahuan atau kepentingan memanfaatkan media pembelajara tersebut akhirnya dapat menuntun guru untuk menciptakan situasi pembelajaran sesuai dengan konten yang tepat. 


\section{DAFTAR PUSTAKA}

Ainiyah, N. (2017). Membangun Penguatan Budaya Literasi Media dan Informasi Dalam Dunia Pendidikan. Jurnal Pendidikan Islam Indonesia, 2(1), 65-77.

Anggaraeni, F. D., \& Rola, F. (2017). Literasi Informasi Pada Guru. Prosiding SEMNAS Penguatan Individu di Era Revolusi Informasi

Hapsari, A., Novitasari, R., \& Wahyuningsih, H. (2018). Pelatihan Literasi Sumber dan Bahan Belajar di Internet bagi Guru PAUD di Kecamatan Ngaglik, Sleman. Jurnal Pengabdian Pada Masyarakat, 3(2), 135-140.

Kharizmi, M. (2019). Kesulitan siswa sekolah dasar dalam meningkatkan kemampuan literasi. Jurnal Pendidikan Almuslim, 7(2).

Pratiwi, N., \& Pritanova, N. (2017). Pengaruh Literasi Digital terhadap Psikologis Anak dan Remaja. Semantik, 6(1), 11-24.

Rahman, M. T., \& Bukhori, B. (2016). Pelatihan Literasi Media: Pengabdian Kepada Masyarakat Desa Cibeureum Kecamatan Kertasari Kabupaten Bandung.

Sari, R. H. N. (2015, November). Literasi Matematika: Apa, Mengapa, dan Bagaimana. In Prosiding Seminar Nasional Matematika dan Pendidikan Matematika UNY (p. 714).

Saepudin, E., \& Damayani, N. A. (2016). Literasi Media Bagi Guru Paud Di Kecamatan Cicalengka. Dharmakarya, 5(1).

Yusup, P. M., \& Saepudin, E. (2017). Praktik Literasi Informasi Dalam Proses Pembelajaran Sepanjang Hayat (Information Literacy Practices In The Process Of Lifelong Learning). Jurnal Kajian Informasi \& Perpustakaan, 5(1), 79-94. 